\title{
Lingüística
}

Vol. 36-2, diciembre 2020: 107-129

ISSN 2079-312X en línea

DOI: $10.5935 / 2079-312 X .20200017$

\section{ELEMENTOS PARA UMA ABORDAGEM INTERACIONISTA DAS RELAÇÕES DE DISCURSO}

\author{
ELEMENTOS PARA UN ABORDAJE INTERACCIONISTA DE LAS RELACIONES DEL \\ DISCURSO
}

ELEMENTS FOR AN INTERACTIONIST APPROACH OF DISCOURSE RELATIONS

\author{
Gustavo Ximenes Cunha ${ }^{1}$ \\ Universidade Federal de Minas Gerais \\ ximenescunha@yahoo.com.br \\ 0000-0001-9953-1204
}

\section{Resumo}

Articulando contribuições teóricas de autores que concebem a linguagem e o contexto em uma perspectiva interacionista, este trabalho apresenta elementos para uma abordagem do papel das relações de discurso e suas marcas na construção de imagens identitárias ou na dimensão dramatúrgica do discurso. Subjaz a essa abordagem a hipótese de que as relações de discurso que o locutor estabelece entre as informações expressas em sua intervenção Ihe permitem antecipar-se a possíveis objeções do outro (interlocutor ou terceiro) quanto à natureza ofensiva dessa intervenção, na busca por fazer com que o outro não avalie essa intervenção como um ataque à sua face ou uma invasão de seu território. A fim de verificar a pertinência dessa hipótese em que a abordagem se sustenta, propomos o estudo do papel das relações de argumento e contra-argumento marcadas respectivamente pelos conectores porque e mas na dimensão dramatúrgica de um debate eleitoral.

Palavras-chave: dimensão dramatúrgica do discurso; relações de discurso; interação.

\section{Resumen}

Articulando aportes teóricos de autores que conciben el lenguaje y el contexto en una perspectiva interaccionista, este trabajo presenta elementos para una aproximación al papel de las relaciones discursivas y sus marcas en la

1 Gustavo Ximenes Cunha agradece ao CNPq a concessão da bolsa de Produtividade em Pesquisa (nível 2). Processo: 304244/2019-8. 
construcción de imágenes identitarias o en la dimensión dramatúrgica del discurso. Detrás de este planteamiento se encuentra la hipótesis de que el hablante establece relaciones de discurso que le permiten anticipar posibles objeciones del otro (interlocutor o tercero) respecto al carácter ofensivo de esta intervención, procurando hacer que el otro no evalúe esta intervención como un ataque a su imagen o una invasión a su territorio. Para verificar la relevancia de esta hipótesis en la que se sustenta el enfoque, proponemos estudiar el papel de las relaciones argumento y contraargumento marcadas respectivamente por los conectores porque y mas en la dimensión dramatúrgica de un debate electoral.

Palabras-clave: dimensión dramatúrgica del discurso; relaciones de habla; Interacción.

\begin{abstract}
Articulating theoretical contributions from authors who conceive language and context in an interactionist perspective, this paper presents elements for an approach to the role of discourse relations and their marks in the construction of identity images or in the dramaturgical dimension of discourse. This approach is based on the hypothesis that the speaker establishes discourse relations in order to anticipate possible objections of the other (interlocutor or third party) about the offensive nature of this intervention. Establishing these relationships, the speaker tries to make the other do not evaluate this intervention as an attack on his face or an invasion of his territory. In order to verify the pertinence of this hypothesis, we propose the study of the role of the argument and counter-argument relations marked respectively by the connectors porque [because] and mas [but] in the dramaturgical dimension of an electoral debate.
\end{abstract}

Key-words: dramaturgical dimension of discourse; discourse relations; interaction.

Recebido: $02 / 01 / 2019$

Aceito: $11 / 06 / 2019$

\title{
1. Introdução
}

Tradicionalmente, o estudo das relações de discurso (ou, conforme a perspectiva teórica, relações textuais, semânticas, retóricas) se ocupa dos aspectos estruturais e informacionais dessas relações e de problemáticas conexas, como definição e categorização dos marcadores discursivos, identificação das propriedades de conectores pragmáticos e de formas verbais sinalizadoras de relações de discurso, especificação das relações de sentido que subjazem aos encadeamentos de atos de fala etc. 
Delimitando o interesse de algumas abordagens que, nas últimas décadas, têm tido influência nos estudos do texto e do discurso, verificamos que com elas busca-se, de modo geral:

- descrever a articulação de frases ou de enunciados por meio de instruções codificadas em itens da língua, como conectores e operadores, que autorizam determinados encadeamentos e bloqueiam outros (Ducrot, Rossari);

- explicar como informações expressas em um enunciado incrementam o contexto (ambiente cognitivo imediato) necessário para a compreensão do enunciado seguinte e como a presença de um conector ligando esses enunciados diminui os esforços de processamento requeridos para se inferir a relação entre eles (Blakemore, Moeschler, Luscher);

- analisar o texto como o resultado da emergência de diferentes proposições relacionais ou relações retóricas (elaboração, antítese, evidência etc.) entre unidades de extensão e natureza variadas, como sentenças e parágrafos (Mann, Thompson, Matthiessen);

- estudar os mecanismos coesivos (coesão referencial e coesão sequencial) que auxiliam o autor/falante na articulação de partes do texto, contribuindo para a construção da coerência pelo leitor/ouvinte (Halliday, Hasan, Adam, Charolles).

Ainda que, em muitas abordagens, ressalte-se que a frase, o enunciado ou o texto resulta de um processo interacional ou um fenômeno construído para e em função de um interlocutor ${ }^{2}$, o interesse maior está em descrever como unidades sócio-cognitivas (conceitos, referentes, objetos de discurso), textuais (orações, sentenças, intervenções) ou pragmáticas (enunciados, atos de fala) se articulam para formar uma frase, um enunciado ou um texto.

Porque essas abordagens se centram na descrição das relações que emergem da articulação de diferentes unidades e das marcas que as sinalizam, não faz parte de seu escopo ou não constitui sua finalidade primeira investigar o papel que essas mesmas relações e suas marcas desempenham na dimensão dramatúrgica do discurso, ou seja, no plano de construção conjunta de imagens identitárias pelos interactantes (Goffman 2011, 1973, Filliettaz 2000). Com essas abordagens, não se busca, assim, aferir em que medida argumentar, contra-argumentar, comentar, reformular constituem manobras que revelam quem sou eu para o outro e para mim; quem é o outro para mim e para $\mathrm{si}^{3}$.

Por isso, como apontado em Cunha (2017a), as indicações disponíveis desse papel são pontuais e não permitem a constituição de uma abordagem única para o estudo da maneira como as relações de discurso e suas marcas permitem aos interactantes construírem imagens de si e do(s) outro(s), ao longo da interação.

\footnotetext{
${ }^{2}$ Esse é o caso, em especial, de abordagens funcionalistas (Halliday e Hasan 1976, Mann e Thompson 1986, Neves 2006) e da Linguística do Texto (Adam 2006, Koch 2004).

3 Exceção importante nesse quadro são os trabalhos de Landone (2012a, 2012b, 2017), em que os marcadores discursivos, categoria que, na proposta da autora, abarca conectores e, sobretudo, marcadores conversacionais, são estudados à luz de teorias da polidez.
} 
Partindo dessa lacuna, este trabalho apresenta elementos para uma abordagem do papel das relações de discurso e suas marcas na construção de imagens identitárias ou na dimensão dramatúrgica do discurso. Subjaz a essa abordagem interacionista a hipótese de que as relações de discurso que o locutor estabelece entre as informações que expressa permitem a ele antecipar-se a possíveis objeções do outro (interlocutor ou terceiro) quanto à natureza ofensiva de sua intervenção, na busca por fazer com que o outro não avalie essa intervenção como um ataque à sua face ou uma invasão de seu território. Com as relações que estabelece, o locutor tenta impedir, desse modo, que o outro inicie uma troca reparadora, troca que, por ter como fim exatamente reparar a ofensa cometida pelo locutor, é sempre perigosa para sua face e seu território.

A apresentação dessa abordagem e da hipótese em que se assenta será feita em quatro momentos. Partiremos da noção de contexto, revelando que uma abordagem tal como a que delineamos implica uma concepção interacionista de contexto, da qual participa a noção de dimensão dramatúrgica do discurso. Em seguida, explicitaremos as noções de interação e de relações de discurso que consideramos adequadas em tal abordagem. Em um terceiro momento, com base nas definições propostas nas primeiras seções, discutiremos o papel das relações de discurso na construção de imagens identitárias ou na dimensão dramatúrgica do discurso. Por fim, ilustraremos como essa abordagem pode ser empregada na compreensão do papel das relações de argumento e contra-argumento marcadas respectivamente pelos conectores porque e mas na dimensão dramatúrgica de um debate eleitoral.

\section{2. $O$ contexto em uma perspectiva interacionista}

Em uma pesquisa cuja finalidade central é evidenciar o papel das relações de discurso e de suas marcas na dimensão dramatúrgica do discurso, propondo elementos para uma abordagem interacionista dessas relações, a definição do que se entende por contexto assume uma importância especial. Isso porque, como se discute neste item, a dimensão dramatúrgica é constitutiva do contexto e resulta das ações linguageiras e não linguageiras realizadas pelos interactantes, ações de que fazem parte as relações de discurso. Assim, o estabelecimento de relações de discurso permite aos interactantes se apresentarem e se representarem de determinada maneira (dimensão dramatúrgica).

$\mathrm{Na}$ perspectiva interacionista adotada neste trabalho ${ }^{4}$, o contexto corresponde ao conjunto dos elementos de natureza sócio-histórica que são, de fato, significativos para os interactantes participarem de uma interação. Para extrair o conjunto desses elementos ou, pelo menos, uma parte deles, deve-se compreender o contexto como um fenômeno resultante da articulação tanto de ingredientes externos ao contato social, os quais pré-existem à

\footnotetext{
4 Apresentações dos princípios que caracterizam a vertente interacionista dos estudos da linguagem encontram-se em Kerbrat-Orecchioni (1992), Roulet et al. (2001, cap. 1), Morato (2004).
} 
interação efetivamente realizada, quanto de ingredientes internos ao contato social e, portanto, negociados pelos interactantes no próprio desenvolvimento da interação. Desse modo, o contexto possui uma dimensão esquemática (elementos sócio-históricos que modelam a interação) e uma dimensão emergente (a negociação de que esses elementos são objeto pelos interactantes) (Filliettaz 2003, 2006, Watts 2003, Cunha 2013, 2017b).

Do ponto de vista esquemático, interagir implica mobilizar saberes (normas, crenças, valores) cultural e historicamente constituídos e, portanto, anteriores à própria interação.

Em diferentes abordagens interacionistas do texto e do discurso (Vion 1992, Kerbrat-Orecchioni 1992, Roulet et al. 2001, Bronckart 2007, Culpeper 2008, 2011), verifica-se um esforço em delimitar e precisar os saberes estabilizados que, resultantes de um processo sócio-histórico ao longo do qual modos de agir são (re)experienciados por gerações de interactantes, os guiam, de modo mais ou menos rígido, na interação e lhes possibilitam perceber, nessa interação, quais ações linguageiras e não linguageiras são esperadas ou inesperadas, adequadas ou inadequadas.

Nessas abordagens, alguns dos saberes recorrentemente levados em conta são: conhecimentos sobre como agir em determinado tipo de interação (gêneros do discurso, quadros da experiência, tipos de atividade social); os objetivos característicos de cada tipo de interação (informar, ensinar, divertir); os status (papéis) sociais assumidos pelos interactantes, status que, por sua natureza sócio-histórica, vinculam a cada interactante determinados direitos, deveres e poderes em relação ao(s) outro(s) interactante(s); as identidades social e individual concebidas como conjunto de traços institucionais e biográficos capazes de imprimir uma "personalidade" relativamente estável em cada interactante; a materialidade própria de cada tipo de interação (número de interactantes, existência ou não de reciprocidade entre eles, distância ou co-presença espacial e temporal entre eles, canal oral, escrito e/ou visual).

Do ponto de vista emergente, interagir significa negociar esses saberes que, esquematicamente, enquadram a interação. Ainda que as restrições relativas à dimensão esquemática do contexto tenham impacto considerável sobre o desenvolvimento da interação, sobretudo das que se caracterizam por uma rigidez maior na realização das ações (audiências, consultas médicas etc.), os interactantes têm a capacidade de negociar (ratificar ou subverter total ou parcialmente) as expectativas relativas à situação, o que se evidencia nos ajustes que cada interactante é levado a fazer in loco para adaptar os saberes de que dispõe aos saberes apenas parcialmente compartilhados com $o$ (s) outro(s). Nesse sentido, as interações se caracterizam sempre por ajustes das linhas de conduta efetivamente seguidas no desenvolvimento da interação (Filliettaz 2003, 2006, Watts 2003, Spencer-Oatey 2007, Filliettaz et al. 2018).

Porque os interactantes são capazes de negociar essas expectativas, avaliando, em razão de como agem, quem são um(uns) para o(s) outro(s), entendemos que um elemento essencialmente emergente da interação é sua dimensão dramatúrgica (Goffman 2009, 2011), ou seja, as imagens identitárias construídas conjuntamente pelos interactantes, em função da linha de conduta que seguem na interação. 
Baseando-nos em grande parte da literatura sobre o tema, consideramos que a dimensão dramatúrgica do discurso comporta duas noções essenciais: face e território ${ }^{5}$. A primeira corresponde ao "valor social positivo que uma pessoa efetivamente reivindica para si mesma através da linha que os outros pressupõem que ela assumiu durante um contato particular" ou à "imagem do eu delineada em termos de atributos sociais aprovados" (Goffman 2011: 1314). A segunda - território - corresponde aos elementos físicos e simbólicos que, constituindo uma reserva pessoal de cada interactante, costuma ser por ele preservada e defendida na interação; corresponde ainda a seus direitos e desejos de estar e permanecer em liberdade e de não sofrer imposição (Goffman 1973, Brown e Levinson 1987).

Na perspectiva que seguimos, as imagens identitárias - faces e territórios - dos interactantes constituem fenômenos emergentes, já que, embora sejam parcialmente condicionadas por expectativas sócio-históricas (quais faces os interactantes podem/devem reivindicar na interação; quanto de seus territórios pode/deve ser exposto ou preservado), são, sobretudo, o resultado da linha de conduta seguida por eles na interação e não algo radicalmente prédefinido.

Assim, ainda que os status (papéis) sociais impactem o modo como os interactantes se apresentam e se representam na interação (Vion 1992, Holtgraves 1994, Scollon e Scollon 2001), é na interação mesma, em virtude da linha de conduta efetivamente seguida pelos interactantes, que estes avaliam se essa linha corresponde ou não às suas expectativas para o contexto e, desse modo, constroem imagens identitárias ou representações de quem sou eu para o outro e para mim e de quem é o outro para mim e para si (Watts 2003, 2005, Locher e Watts 2008) ${ }^{6}$.

Como as relações de discurso que os interactantes estabelecem no curso da interação são parte de sua linha de conduta, a construção conjunta das imagens identitárias se faz de forma dinâmica, à medida que as relações vão sendo estabelecidas. Assim, é porque, a cada momento da interação, os interactantes buscam evitar ou promover ataques às faces e aos territórios em jogo que eles estabelecem ou deixam de estabelecer relações de argumento, contra-argumento, comentário, preparação, reformulação etc.

Desse ponto de vista, o estabelecimento das relações de discurso e a dimensão dramatúrgica do discurso surgem como fenômenos fortemente articulados.

5 Partindo, de modo geral, de Goffman (1973, 2009, 2011), o estudo da dimensão dramatúrgica do discurso tem se desenvolvido, em especial, no âmbito das teorias da (im)polidez, a partir das contribuições pioneiras de Lakoff (1977), Leech (1983) e Brown e Levinson (1987). Em Brown e Levinson (1987), abordagem que, nas últimas décadas, tem suscitado maior número de aplicações, críticas e debates, as noções de face e território são reinterpretadas, respectivamente, como face positiva e face negativa. Para uma apresentação do campo das teorias da (im)polidez, cf. Culpeper (2011), Culpeper e Terkourafi (2017).

6 Nesse sentido, é válida a distinção proposta por Bousfield (2018) entre as noções de identidade e imagem identitária (face). Enquanto a primeira noção possui uma natureza mais esquemática (estável), a segunda, embora se alimente da primeira, possui uma natureza mais emergente, por ser algo que se constrói fundamentalmente na interação. 


\section{O papel das relações de discurso no processo de negociação}

Como exposto, o plano emergente do contexto se constrói no desenvolvimento da própria interação. Em consultas médicas, por exemplo, espera-se que perguntas sobre o estado de saúde sejam feitas apenas pelo médico e que, feitas as perguntas, o paciente responda, sem questionar a legitimidade do médico em fazer perguntas dessa natureza ou sem evidenciar incômodo por ter seu território (seu estado de saúde) invadido. Mas, se, em uma dada consulta, um dos interactantes ou todos subvertem essas expectativas, a linha de conduta inesperada terá um impacto sobre a dimensão dramatúrgica da interação ou sobre a maneira como os interactantes se percebem e avaliam suas ações.

Dessa forma, é por meio da linha de conduta efetivamente seguida pelos interactantes que se revela a dimensão dramatúrgica de uma interação. Como exposto, parte essencial da linha de conduta dos interactantes são as relações de discurso que estabelecem. Nesta pesquisa, adotamos as proposições de Roulet para o tratamento das relações de discurso e suas marcas, em virtude da orientação cognitivo-interacionista de sua abordagem para o estudo da complexidade discursiva (Roulet et al. 2001, Roulet 2003, 2006). Subjaz ao estudo das relações de discurso proposto por Roulet a noção de processo de negociação. Para o autor, a interação deve ser entendida como uma negociação ou um processo por meio do qual os interactantes negociam a intencionalidade característica do encontro, com base em suas intencionalidades individuais (Roulet 1992) ${ }^{7}$.

Nessa perspectiva, a estrutura de toda troca verbal resulta desse processo de negociação, que, como propõe o autor, está submetido a dois tipos de restrições: a de completude dialógica e a de completude monológica. A restrição de completude dialógica diz respeito ao alcance do duplo acordo. Conforme Roulet,

toda negociação tem sua origem em um problema que dá lugar a uma iniciativa do locutor; essa iniciativa pede uma reação, que pode ser favorável ou desfavorável, do interlocutor. Se ela é favorável, o locutor pode encerrar a negociação, exprimindo, por sua vez, seu acordo. (Roulet et al. 1985: 15).

Quando a reação do interlocutor à proposição inicial do locutor é favorável, a interação se representa por meio de uma estrutura de troca formada por três intervenções, cada uma correspondendo a uma etapa do processo de negociação: proposição, reação e ratificação. É o que exemplifica este diálogo: A: Que horas são? B: São 9 horas. A: Obrigado. (No exemplo 1, troca $=\mathrm{T}$, intervenção $=\mathrm{I}$ ).

\footnotetext{
7 Por exemplo, em uma livraria, a intencionalidade compartilhada por livreiro e cliente (transação de compra e venda de livros) é negociada, ao longo da interação, em função da intencionalidade de cada um (enquanto o livreiro quer vender livros, o cliente quer comprá-los) (Roulet 1995, Filliettaz 2004).
} 
Ex. 1 - Troca 1

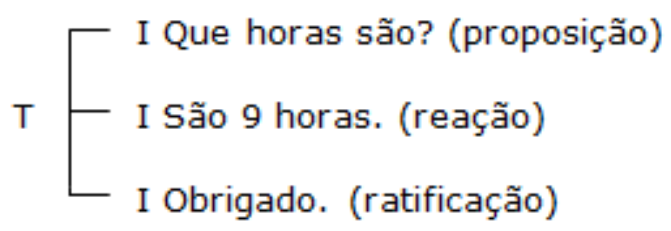

Porém, quando a reação do interlocutor à proposição inicial é desfavorável (recusa em aceitar um convite ou em dar uma informação, por exemplo), a negociação não pode ser encerrada. A reação desfavorável pode levar o locutor a realizar uma contra-proposição, reelaborando sua proposição inicial.

Enquanto a completude dialógica não for alcançada, a interação se desenvolve, a menos que os interactantes percebam a impossibilidade de alcançarem o duplo acordo, como costuma ocorrer, por exemplo, em brigas acaloradas ou em debates eleitorais (Cunha 2017b). Nesse caso, a estrutura da troca se estende, podendo comportar bem mais do que apenas três intervenções, como ocorre neste diálogo: A: Que horas são? B: Não sei. A: Por que não olha seu relógio? B: Ele parou de funcionar. (Exemplo 2).

Ex. 2 - Troca 2

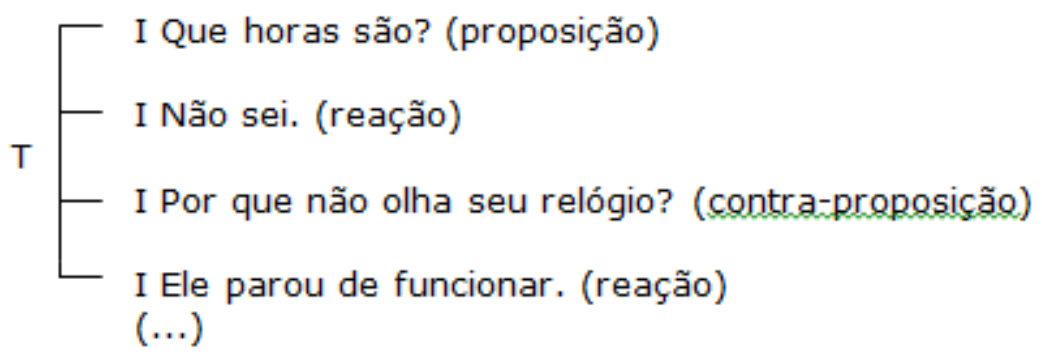

Além da restrição de completude dialógica, os interactantes devem satisfazer ainda outra restrição, a de completude monológica, para que a negociação possa se desenvolver. Essa restrição diz respeito à necessidade de o locutor elaborar cada etapa do processo de negociação - proposição, reação ou ratificação - de modo suficientemente adequado e completo dos pontos de vista comunicativo e ritual $^{8}$, para que seja possível o desenvolvimento da negociação pelo interlocutor.

Mas, em qualquer contexto, o julgamento sobre a completude de uma intervenção (se ela é, de fato, válida para o processo de negociação) não cabe ao próprio locutor. É ao interlocutor, em função dos parâmetros do contexto em que se encontra, que cabe a tarefa de avaliar se essa intervenção the permite produzir uma reação ${ }^{9}$.

\footnotetext{
$8 \mathrm{Em}$ linhas gerais, os problemas comunicativos caracterizam intervenções que violam quaisquer das máximas conversacionais de Grice (quantidade, qualidade, relevância, modo). Já os problemas rituais caracterizam as intervenções que atacam as faces e os territórios em jogo (Goffman 1973, 1981, Roulet et al. 1985). No próximo item, retomaremos essa distinção, para verificarmos que ela é mais complexa e menos nítida do que pode parecer à primeira vista.

9 "Somente este [o interlocutor] pode julgar, em último caso, se a intervenção do locutor lhe fornece todos os elementos necessários para que ele possa tomar posição, exprimir seu acordo ou seu desacordo" (Roulet et al. 1985: 17).
} 
Se ele julgar a intervenção inadequada, poderá iniciar um processo de negociação secundário, pedindo esclarecimentos ao locutor, para que ele, interlocutor, possa, após os esclarecimentos, desenvolver a negociação principal. A abertura de uma negociação secundária pelo interlocutor se materializa em uma troca subordinada à intervenção do locutor. É o que exemplifica este diálogo: A: Vamos ao cinema? B: A que horas? A: Às 8 da noite. B: Vamos sim! Nesse diálogo, para $B$ reagir favoravelmente ao convite de $A$, ele precisou iniciar uma negociação secundária (B: A que horas? A: Às 8 da noite.) que evidenciou que, para B, o convite de A (Vamos ao cinema?) estava incompleto do ponto de vista monológico, não lhe permitindo reagir. Essa análise se representa no exemplo 3 (troca $=\mathrm{T}$, intervenção $=\mathrm{I}$, principal $=\mathrm{p}$, subordinada $=\mathrm{s}$ ).

Ex. 3 - troca 3

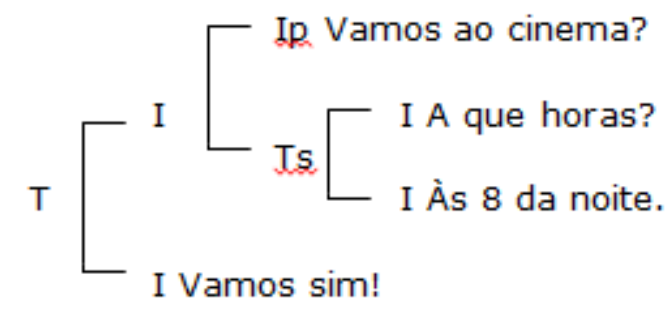

Nessa perspectiva da interação como negociação, as relações de discurso estão ligadas às restrições de completude dialógica e monológica. Como exposto em Marinho e Cunha (2015) e Cunha (2017b), fazer uma concessão, impor condições, agradecer, aceitar/recusar uma proposta, reformular uma informação ou sustentar um ponto de vista com argumentos são manobras que, componentes da linha de conduta seguida pelos interactantes, Ihes permitem tentar produzir uma intervenção suficientemente adequada para a negociação em curso, reagir à proposição, ratificar uma reação, iniciar uma negociação secundária, solicitando esclarecimentos etc.

Roulet propõe dois tipos de relações de discurso: as ilocucionárias, cujo estabelecimento está ligado à restrição de completude dialógica, e as interativas, cujo estabelecimento está ligado à restrição de completude monológica. Para cada um dos tipos, o autor propõe categorias genéricas de relações. As categorias de relações ilocucionárias são: iniciativas (pergunta, pedido e asserção) e reativas (resposta e ratificação). Para Roulet, o valor ilocucionário (pergunta, pedido, asserção etc.) caracteriza não o ato isolado, como na teoria dos atos de fala (Austin 1962, Searle 1995), mas a relação que uma intervenção (formada por um ou muitos atos, intervenções e trocas) estabelece com as informações expressas na intervenção posterior e na intervenção anterior (Roulet 1980, 1999, Roulet et al. 2001).

Já as categorias de relações interativas são: argumento, contraargumento, reformulação, topicalização, tempo (sucessão), preparação, comentário, clarificação (Roulet 2003, 2006, Cunha 2012). Essas relações correspondem a manobras cujo fim é permitir aos interactantes atenderem à restrição de completude monológica, elaborando uma intervenção que considerem satisfatória para o desenvolvimento da interação. 
Assim, o locutor, ao estabelecer uma relação interativa, evidencia sua busca por produzir uma intervenção que possa ser considerada suficientemente adequada pelo interlocutor, a ponto de permitir a este desenvolver o processo de negociação, expressando sua reação ou sua ratificação. Já o interlocutor, se percebe (julga, avalia) que a intervenção do locutor não satisfaz à restrição de completude monológica, pode iniciar uma negociação secundária, que se materializa em uma troca subordinada ligada à intervenção do locutor por uma relação interativa de clarificação. Esse processo é representado no exemplo 4 (troca $=T$, intervenção $=I$, ato $=A$, principal $=p$, subordinado $=s$, pergunta $=P e$, resposta $=R e$, argumento $=$ arg, clarificação = cla).

Ex. 4 - troca 4

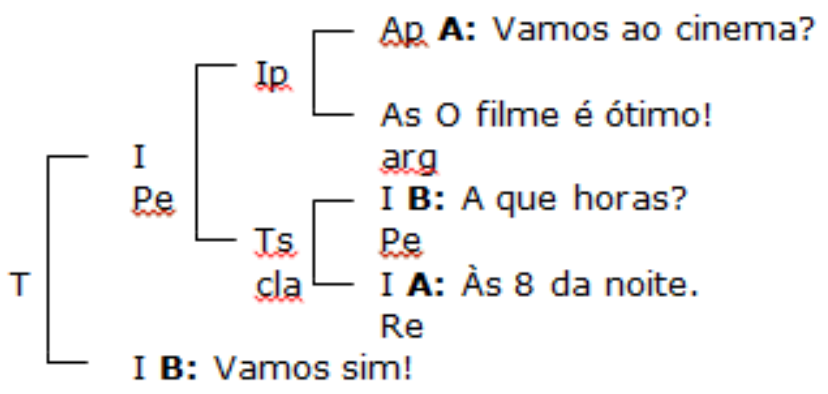

$\operatorname{Re}$

No exemplo 4, a estrutura representa a tentativa de A de fazer com que a intervenção principal atenda à restrição de completude monológica, estabelecendo uma relação de argumento. Nessa intervenção, ele subordina ao ato principal (Vamos ao cinema?) um ato em que justifica o convite ( $O$ filme é ótimo!). A estrutura representa ainda, por meio da troca subordinada com função de clarificação, a percepção de B de que a intervenção principal não está, para ele, suficientemente adequada e não atende, portanto, à restrição de completude monológica, já que nela A não deu informações sobre o horário do filme ${ }^{10}$.

Quanto às marcas das relações de discurso, as relações ilocucionárias são sinalizadas por construções sintáticas (declarativa, interrogativa, imperativa) e por verbos performativos (ordenar, prometer, perguntar etc.). Já as interativas são sinalizadas por conectores (mas, porque, portanto, aliás, por exemplo etc.) e por construções sintáticas, como o deslocamento de constituintes à esquerda do ato em que ocorrem, sinalizando a relação de topicalização (Roulet et al. 1985, Roulet et al. 2001). Como será discutido no próximo item, o processo de negociação e, mais especificamente, o estabelecimento das relações de discurso estão diretamente ligados à dimensão dramatúrgica do discurso.

10 Como as relações ilocucionárias e interativas apresentadas correspondem a categorias genéricas de relações de discurso, cada relação abarca um conjunto de relações específicas. Por exemplo, a relação de argumento é uma categoria genérica que abarca as relações específicas de causa, exemplificação, argumento potencial (condição), argumento suplementar etc. Na abordagem de Roulet, a identificação dessas relações específicas se faz com base em um cálculo inferencial em que as informações de natureza linguística, textual e situacional do texto em análise constituem premissas para a obtenção da interpretação final acerca de qual relação específica liga um constituinte do texto a uma informação da memória discursiva (conhecimentos partilhados pelos interactantes) (Roulet et al. 2001, Roulet 2003, 2006). 
Segundo nossa hipótese exposta na Introdução, o locutor estabelece uma relação de discurso com o fim de se antecipar a possíveis objeções do interlocutor ou de terceiros quanto à completude de sua intervenção, objeções que se manifestam na abertura de uma troca subordinada com função de clarificação ou, nos termos de Goffman (1973), de uma troca reparadora.

A abertura de uma troca dessa natureza sempre põe em perigo as imagens identitárias dos interactantes, seja por permitir ao interlocutor revelar que o locutor o ofendeu, seja por constituir ela mesma uma ofensa ao locutor, que, com a abertura da troca, é "avisado" de que adotou, na elaboração de sua intervenção, uma linha de conduta julgada equivocada para o contexto. Nesse sentido, a compreensão da dimensão dramatúrgica de qualquer produção discursiva implica o estudo do modo como, no desenvolvimento do processo de negociação, os interactantes estabelecem as relações de discurso.

\section{As relações de discurso como recursos linguageiros do processo de figuração}

Conforme já expusemos, a dimensão dramatúrgica do discurso é um aspecto essencialmente emergente do contexto, porque diz respeito à maneira como os interactantes constroem juntos imagens identitárias (faces e territórios), negociando as expectativas (normas, valores, crenças) que enquadram o contexto.

Como a dimensão dramatúrgica de uma interação se revela, em especial, pela linguagem que os interactantes empregam, propomos chamar de processo de figuração o processo por meio do qual eles se valem de todo e qualquer plano da organização do discurso (sintaxe, prosódia, marcas de intertextualidade, tipos e sequências textuais, relações de discurso, cadeia referencial etc.) para construírem imagens identitárias, (re)avaliando, a cada passo da interação e por meio da linguagem, quem são um(uns) para o(s) outro(s). Assim, as imagens identitárias construídas conjuntamente em uma dada interação (sua dimensão dramatúrgica) são o resultado ou o efeito de todas as ações linguageiras e não linguageiras (linha de conduta) executadas ao longo da interação.

Nesse sentido, o processo de figuração corresponde ao aspecto discursivo da dimensão dramatúrgica ou à maneira como os interactantes empregam a linguagem para concretizar ("discursivizar") essa dimensão ${ }^{11}$.

\footnotetext{
11 Processo de figuração (processus de figuration) é a expressão com que Roulet traduz a expressão face work de Goffman (2011). Nos trabalhos iniciais de Roulet sobre a articulação do discurso (Roulet et al. 1985), a processus de figuration correspondia, de fato, a uma tradução da expressão inglesa. Porém, à medida que a proposta do autor evolui de uma abordagem centrada na articulação de atos de fala para uma abordagem voltada para o estudo global da complexidade discursiva, a expressão processus de figuration passa a designar, como argumenta-se em Cunha (2017a), o processo mais amplo por meio do qual os interlocutores se valem do conjunto das estratégias discursivas, pertencentes a diferentes planos de organização do discurso, para realizarem a gestão de faces, territórios e lugares, construindo conjuntamente imagens identitárias e concretizando ("discursivizando") a dimensão dramatúrgica do discurso (Roulet 1999, Roulet et al. 2001). Por isso, neste trabalho, empregamos a expressão processo de figuração e não a expressão mais corrente trabalho de face (face work).
} 
Nessa perspectiva, as relações de discurso (ilocucionárias e interativas) e suas marcas (conectores, estruturas sintáticas etc.) constituem um subconjunto dos recursos linguageiros usados pelos interactantes para realizarem o processo de figuração, uma vez que parte essencial da linha de conduta que seguem corresponde ao estabelecimento das relações de discurso, ou seja, às manobras que realizam com o fim de atenderem às restrições de completude dialógica e monológica.

Considerando que as relações ilocucionárias (pergunta, resposta, pedido etc.) e seu papel no desenvolvimento da interação foram bem descritos nas propostas iniciais da abordagem de Roulet (1986, 1988, Roulet et al. 1985) e que a longa tradição de estudos sobre os atos de fala, bem como as teorias da (im)polidez dão indicações importantes para a compreensão dessas relações no processo de figuração, este trabalho se centra no papel das relações interativas (argumento, comentário, reformulação etc.). No item anterior, vimos que essas relações permitem ao locutor tentar produzir uma intervenção que seja considerada pelo interlocutor como suficientemente adequada para o desenvolvimento da interação. Por isso, elas estão ligadas à restrição de completude monológica.

Para compreendermos o papel das relações interativas no processo de figuração, é necessário definirmos a natureza dos problemas comunicativos e rituais que podem fazer com que um interactante (interlocutor ou terceiro) avalie a intervenção do locutor como inadequada para o desenvolvimento da interação. Definindo esses problemas, entenderemos melhor em que medida o estabelecimento dessas relações constitui um recurso usado pelo locutor para tentar se antecipar a possíveis objeções do outro, evitando-as.

A distinção entre os aspectos comunicativos e rituais da interação é proposta por Goffman (1981) e retomada por Roulet et al. (1985). Os problemas comunicativos, em linhas gerais, caracterizam as intervenções que violam quaisquer das máximas propostas por Grice (1975). Assim, intervenções com problemas comunicativos são aquelas que podem ser consideradas pouco ou excessivamente informativas (quantidade); que se constroem com informações abertamente falsas (qualidade); que trazem informações irrelevantes (relevância); que podem ser consideradas pouco claras - obscuras, ambíguas, prolixas (modo).

Já os problemas rituais caracterizam as intervenções que atacam as faces e os territórios dos interactantes. Goffman (1973: 73) define o ritual como "um ato formal e convencionalizado pelo qual um indivíduo manifesta seu respeito e sua consideração a um objeto de valor absoluto". Entendendo que, nas sociedades ocidentais, o eu é um objeto sagrado ou de valor absoluto, observa o autor que, nas interações cotidianas, os interlocutores realizam rituais semelhantes aos religiosos descritos por Durkheim (1996). Em seu estudo de religiões ditas primitivas, Durkheim propõe a existência de dois tipos de rituais religiosos: o positivo e o negativo. Com o primeiro, o crente presta homenagens, por meio de preces, festas, cerimônias, sacrifícios e oferendas, à entidade sagrada, da qual, assim agindo, se aproxima. Com o ritual negativo, o crente mantém distâncias e evita o contato (ou proíbe-se do contato) com a mesma entidade, expressando temor, respeito, humildade, deferência e veneração. 
Baseando-se nessa distinção, Goffman (1973) observa que os encontros sociais mais cotidianos se caracterizam por dois tipos de trocas rituais: as confirmativas e as reparadoras. Os interlocutores, com as trocas confirmativas, realizam rituais positivos, enquanto, com as trocas reparadoras, realizam rituais negativos. As trocas confirmativas são aquelas com que o locutor "presta homenagem" à face que o interlocutor reivindica na interação ou a seu eu sagrado. Exemplo típico são as trocas de cumprimentos e despedidas. Já as reparadoras são as trocas com que o locutor busca reparar uma ofensa causada à face ou ao território do interlocutor. Nessa perspectiva, intervenções com problemas rituais são aquelas que constituem ou um ataque às faces reivindicadas em uma interação, ou uma invasão/intromissão territorial considerada abusiva por qualquer um dos interactantes ${ }^{12}$.

Como salienta Goffman (1981), a distinção entre os aspectos comunicativos e rituais das interações não deve se fazer de forma rígida, por, na prática, não haver uma fronteira clara entre eles. Afinal, o locutor pode elaborar uma intervenção pouco clara, infringindo a máxima de modo, com o fim de não ofender o interlocutor e, portanto, preservar sua face. Como apontam os estudiosos da polidez, estratégias desse tipo costumam ser empregadas na elaboração de críticas, o que tem como objetivo amenizar o grau de agressividade do valor ilocucionário do ato (Brown e Levinson 1987, Kerbrat-Orecchioni 1992, Leech 1983, 2014). Nesse caso, um problema de ordem comunicativa tem como fim deliberado tentar evitar uma ofensa ou um problema de ordem ritual. Já um interlocutor que, em uma troca, critica de forma direta problemas de natureza comunicativa na intervenção produzida previamente pelo locutor (redundâncias, falta de clareza ou menção a informações falsas) evidencia que esses problemas são, para ele, uma ofensa, por violarem algumas de suas expectativas para o contexto, ou seja, suas exigências contextuais de quantidade, modo ou qualidade. Ao mesmo tempo, esse interlocutor ofende tanto a face do locutor, cujos saberes e habilidades são questionados, quanto sua própria face, já que sua crítica pode fazer com que o locutor o veja como arrogante, vaidoso ou autoritário (Culpeper 1996, Harris 2001).

Assim, toda objeção feita por um dos interactantes ao comportamento do outro, mesmo a que recai sobre aspectos estritamente comunicativos, constitui uma ofensa para o alvo da objeção, porque (em grau maior ou menor, dependendo do contexto em que estão inseridos) põe em questão seu saber, suas qualidades de orador ou escritor habilidoso, sua legitimidade para dizer o que diz, seu poder presumido, as qualidades de seu caráter e de sua personalidade etc. Em outros termos, toda objeção de um interactante recaindo sobre a completude monológica da intervenção produzida pelo locutor sempre toca o plano ritual da interação ou sua dimensão dramatúrgica, mesmo quando, por meio dessa objeção, o interactante pareça se ater a aspectos essencialmente comunicativos.

12 No âmbito da Pragmática, se os problemas comunicativos são violações das máximas conversacionais de Grice (1975), os problemas rituais podem ser entendidos como violações das máximas de polidez propostas por Leech (1983, 2014): tato, generosidade, aprovação, modéstia, concordância, simpatia, obrigação (do locutor para o outro), obrigação (do outro para o locutor), reticência de opinião e reticência de sentimento. 
Em uma aula, por exemplo, o professor pode omitir informações, por supor que já são ou deveriam ser do conhecimento dos estudantes. Se essa omissão for avaliada como problemática (ofensiva) por um dos estudantes, este pode iniciar uma negociação secundária, que se materializa em uma troca subordinada com função de clarificação (troca reparadora) em que pede esclarecimentos ao professor. A abertura dessa troca coloca as faces e os territórios em jogo, porque evidencia que, para o estudante, o professor supôs erroneamente que todos possuem determinados saberes (o professor ataca a face do estudante) e, portanto, não foi capaz de produzir uma intervenção adequada para o contexto (o estudante ataca a face do professor). Nesse exemplo, a tentativa de resolver um problema comunicativo provoca um problema ritual.

É nessa perspectiva que se podem entender as relações interativas e suas marcas como recursos de que os interactantes se valem para desenvolver o processo de figuração. O locutor estabelece as relações interativas (argumento, reformulação, comentário etc.) para prevenir ou evitar a abertura de uma troca reparadora pelo interlocutor ou por terceiros, ou seja, para tentar antecipar-se a possíveis objeções quanto a problemas comunicativorituais de sua intervenção.

No exemplo da aula, a ausência de relações de reformulação na fala do professor pode fazer com que os estudantes avaliem suas intervenções como inadequadas (obscuras) e, portanto, ofensivas. Afinal, o professor que elabora uma intervenção julgada inadequada pelos estudantes para o desenvolvimento da interação pode impedir que estes reajam satisfatoriamente, fazendo uma prova, escrevendo uma resenha ou utilizando um programa computacional. Ao agir dessa forma, o professor viola uma expectativa dos estudantes, que, por isso, se veem ofendidos e no direito de repararem suas faces por meio da abertura de trocas reparadoras, trocas que, por trazerem objeções à completude da intervenção do professor, constituem um ataque à sua face e ao seu território. No entanto, estabelecendo relações de reformulação, o professor tenta evitar a abertura dessas trocas.

No próximo item, verificaremos em que medida a abordagem esboçada neste item e nos anteriores sobre as relações de discurso permite compreender, de uma perspectiva interacionista, o papel das relações de argumento e contra-argumento na dimensão dramatúrgica de um debate eleitoral.

\section{As relações de discurso e a dimensão dramatúrgica de um debate eleitoral}

Neste item, com a análise de relações de discurso estabelecidas em um debate eleitoral, procura-se revelar como interactantes precisos (adversários políticos), situados em um contexto determinado (debate eleitoral), utilizam relações de discurso para desenvolver o processo de figuração. Ainda que a finalidade da abordagem proposta seja o estudo das relações de discurso que se estabelecem em todo e qualquer contexto, a escolha de um debate para ilustrar essa abordagem se justifica pelo fato de que, em debates eleitorais, a 
(des)construção conjunta das imagens identitárias é um aspecto maximamente explorado pelos interactantes que deles participam (Blas-Arroyo 2003, Aquino 2008, Martel 2008, Sullet-Nylander e Roitman 2009).

Antes de tratarmos das relações de discurso, faremos breves considerações sobre os aspectos esquemático e emergente do contexto em que foram estabelecidas. Do ponto de vista esquemático, os status (papéis) sociais assumidos pelos interactantes centrais de um debate (candidatos a um cargo político e eleitores) têm impacto sobre a linha de conduta que seguem ${ }^{13}$. Assim, mais do que tornar o eleitor ciente de seu programa de governo, o que cada adversário busca é tentar convencer esse eleitor de que ele é o melhor candidato para o cargo em disputa. Essa tentativa de convencimento se manifesta em uma linha de conduta em que cada um destaca suas supostas qualidades sobre o pano de fundo dos supostos defeitos do outro. Por isso, todo debate costuma se caracterizar pela agressividade e pela polêmica, o que é acirrado pela co-presença espacial e temporal entre os candidatos e pela regulação estrita do tempo de fala de cada um (Cunha e Braga 2016).

Porém, faz parte das expectativas que enquadram um debate o controle dessa agressividade, uma vez que um candidato que age de forma excessivamente agressiva pode ser visto com desconfiança pelo eleitorado. Nesse sentido, a tensão própria de um debate se deve a esse constante controle da agressividade que costuma caracterizar a linha de conduta dos candidatos e que se explica pela presença de um terceiro na interação, o eleitor (Kerbrat-Orecchioni 1995). Embora geralmente não participe da interação como um interlocutor imediato e com direito à fala, é ao eleitor que cabe a tarefa de avaliar a atuação dos adversários ao longo do debate e a adequação (completude) de suas intervenções.

Por esse motivo, as objeções que cada candidato tenta evitar, quando estabelece relações de discurso ao elaborar proposições e reações, são, em especial, as do eleitor e não as do adversário. Essas características que definem esquematicamente todo debate eleitoral são objeto de negociações ao longo de cada debate específico. É por isso mesmo que cada debate se define pela emergência de uma dimensão dramatúrgica própria.

O debate selecionado para análise foi protagonizado pelos então candidatos à Presidência da República Federativa do Brasil, Dilma Rousseff (PT) e Aécio Neves (PSDB), e foi o último debate da campanha presidencial de $2014^{14}$. À época, Dilma Rousseff era a Presidenta da República e pleiteava a reeleição, enquanto Aécio Neves era o candidato da oposição. A materialidade interacional desse debate apresenta especificidades em relação à materialidade típica do debate eleitoral. No estúdio de televisão onde se realizou, havia a presença de uma plateia representando os eleitores, o que pode ter contribuído para aumentar a tensão entre os adversários. Além disso, em momentos pré-determinados, integrantes da plateia faziam perguntas aos adversários.

${ }^{13}$ Outro interactante do debate é o mediador, jornalista cuja função é explicitar parte das normas que estruturam a interação e coibir infrações a essas normas. Em virtude dos objetivos deste trabalho, sua atuação não será aqui considerada.

14 O debate, promovido pela Rede Globo, pode ser acessado em: http://g1.globo.com/politica/eleicoes/2014/transcricao-debate-presidencial-2-turno.html 
Nesses momentos, a materialidade interacional do debate se alterava, já que cada candidato passava a ter um eleitor como interlocutor imediato, enquanto o adversário e os demais eleitores passavam a exercer o papel de terceiro.

Neste trabalho, estudamos a atuação de duas categorias de relações de discurso (as de argumento e contra-argumento marcadas respectivamente pelos conectores porque e mas) como recursos do processo de figuração ou como manobras que, integrantes da linha de conduta dos adversários, Ihes permitiram co-construir a dimensão dramatúrgica dessa interação. Para maior clareza na percepção do papel dessas relações, estudamos apenas as relações estabelecidas pelos candidatos. Assim, não serão consideradas as relações de argumento (porque) e contra-argumento (mas) estabelecidas pelo mediador e por eleitores convidados a fazerem perguntas. Também não serão consideradas as relações de argumento e contra-argumento que, mesmo estabelecidas pelos candidatos, não foram sinalizadas por conectores ou o foram por outros conectores argumentativos e contra-argumentativos. A tabela 1 apresenta o total de ocorrências das relações de argumento e contraargumento marcadas respectivamente por porque e mas no debate, bem como o total de ocorrências na fala de cada candidato.

\begin{tabular}{|l|c|c|c|c|}
\hline \multirow{2}{*}{ Candidatos } & \multicolumn{2}{|c|}{ PORQUE } & \multicolumn{2}{c|}{ MAS } \\
\cline { 2 - 5 } & N & \% & N & \% \\
\hline Aécio Neves & 29 & 54.7 & 22 & 57.9 \\
\hline Dilma Rousseff & 24 & 45.3 & 16 & 42.1 \\
\hline Total & 53 & 100 & 38 & 100 \\
\hline
\end{tabular}

Tabela 1: Ocorrências de conectores no corpus

Iniciaremos a análise com o estudo da relação de argumento marcada pelo porque. Em todas as 53 ocorrências identificadas, o conector é antecedido por ato ou intervenção principal e introduz ato ou intervenção subordinada. Em todas elas, com o constituinte principal, o candidato ataca a face do adversário ou invade seu território, realizando críticas e acusações, ou valoriza sua própria face, apontando méritos de sua própria gestão ou qualidades de seu histórico como figura pública/política. No contexto do debate, o autoelogio de um candidato constitui uma crítica indireta ao adversário (Fracchiolla 2011). Sendo assim, as informações expressas à esquerda do conector constituem, em todas as ocorrências, ataques às imagens que o adversário reivindica na interação, uma vez que, com elas, o candidato viola, sobretudo, as máximas de tato, aprovação, concordância e simpatia (Leech 2014).

Se o candidato não estabelecesse a relação de argumento marcada pelo porque, o adversário e os eleitores poderiam iniciar negociações secundárias (trocas reparadoras) com objeções sobre a completude de sua intervenção, ou seja, sobre a pertinência, a veracidade, a clareza ou o motivo tanto das críticas quanto dos autoelogios. As objeções poderiam ocorrer no próprio debate, em trocas abertas pelo adversário e por eleitores da plateia convidados a fazerem perguntas, ou, por exemplo, em redes sociais, em trocas abertas tanto por eleitores da plateia, quanto por aqueles posicionados à distância. 
Independentemente de sua origem, essas objeções seriam prejudiciais tanto para o território do candidato, já que se veria obrigado a justificar as críticas dirigidas ao adversário, quanto para sua face, já que teria suas críticas ou seus autoelogios postos em dúvida.

Estabelecendo a relação de argumento, o candidato tenta evitar a abertura das trocas, poupando-se, assim, de ataques à sua própria face. Vejamos como a relação de argumento atua no excerto (1), retirado da fala de Dilma Rousseff:

1 DILMA ROUSSEFF: Eu acho que o senhor está mal informado [ao dizer que Dilma deixará o país com uma inflação maior do que aquela que recebeu], porque quem deixou o país com uma inflação maior do que recebeu foi o governo tucano do Fernando Henrique [ex-presidente da República].

No ato "Eu acho que o senhor está mal informado", a candidata critica o adversário, ainda que mitigue bastante o grau de agressividade do ato com o uso de oração modalizadora (eu acho que), da expressão o senhor e de um eufemismo (dizer o senhor está mal informado é menos agressivo do que dizer o senhor está errado). Mas, ao realizar essa crítica, ela ataca a face do adversário (ele cometeu um erro) e invade seu território (ele não dispõe de informações corretas). Se a candidata não estabelecesse a relação de argumento marcada pelo porque, o adversário ou eleitores poderiam iniciar uma negociação secundária (troca reparadora) com objeções ou questionamentos sobre a pertinência da crítica: [adversário] "Por que eu estou mal informado?"; [eleitores] "Por que o adversário está mal informado?".

Tais objeções seriam prejudiciais para o território da candidata, na medida em que a obrigariam a justificar sua crítica, bem como para sua face, na medida em que a apontariam como incapaz de produzir, em um debate, uma intervenção suficientemente adequada (clara). Com a relação, a candidata tenta evitar a abertura da troca, poupando-se, assim, de intromissões em seu território e de ataques à sua face e atacando a face do adversário e de colegas de partido.

No corpus, há uma ocorrência do conector porque que ilustra bem nossa hipótese de que as relações de discurso constituem uma tentativa do locutor de se antecipar a possíveis objeções do outro (interlocutor ou terceiro), para evitar a abertura de uma troca subordinada. A ocorrência foi produzida por Aécio Neves (excerto (2)).

2 AÉCIO NEVES: Não houve qualquer ação do PT ou do governo do PT para que algumas dessas propostas [de combate à corrupção expressas por Dilma Rousseff] pudessem avançar. Por quê? Porque não houve preocupação do PT no combate efetivo à corrupção.

No trecho, a pergunta que o candidato se faz ("Por quê?") simula a objeção que a ele poderiam endereçar os eleitores, caso não justificasse a crítica que endereça à adversária na intervenção que antecede a pergunta. Assim, ele reconstrói em sua intervenção a troca que busca evitar, o que pode ser representado no exemplo 5 (troca $=\mathrm{T}$, intervenção $=\mathrm{I}$, ato $=\mathrm{A}$, principal $=\mathrm{p}$, subordinada $=\mathrm{s}$, clarificação $=$ cla $)$. 
Ex. 5 - troca no debate

I

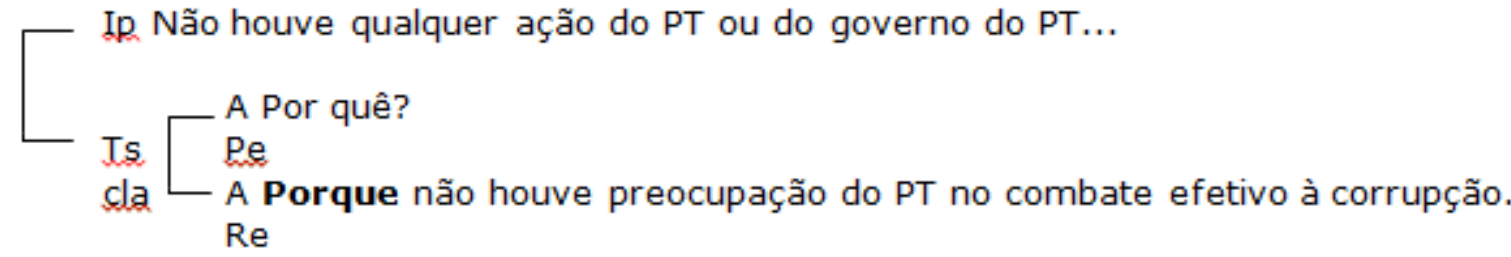

Esse mesmo trecho, sem a objeção e, portanto, sem a abertura da negociação secundária, assume a forma das demais intervenções em que o porque ocorre no corpus (excerto (3)).

3 AÉCIO NEVES: Não houve qualquer ação do PT ou do governo do PT para que algumas dessas propostas pudessem avançar, porque não houve preocupação do PT no combate efetivo à corrupção.

Passemos ao estudo da relação de contra-argumento marcada pelo mas. Nas 38 ocorrências, o conector é antecedido por ato ou intervenção subordinada e introduz ato ou intervenção principal. Em todas elas, o constituinte subordinado que antecede o conector leva a uma conclusão que é, ao mesmo tempo, prejudicial para a face e/ou para o território do próprio locutor e (de segmentos) do eleitorado e benéfica para a face e/ou para o território do adversário. Estabelecendo a relação de contra-argumento marcada pelo mas, o locutor introduz informação que se opõe a essa conclusão ${ }^{15}$. Com a informação introduzida pelo mas, ele tenta evitar o ataque à sua própria face e à de eleitores e ataca a do adversário.

Se o locutor não estabelecesse a relação de contra-argumento, eleitores poderiam iniciar uma negociação secundária (troca reparadora) com objeções acerca da pertinência da conclusão derivada do constituinte à esquerda do conector ("Então, você pensa X ou defende a ideia $Y$ ?"). Por serem prejudiciais para a face do locutor, essas objeções seriam benéficas para a face do adversário. É o que ilustra o excerto (4), extraído da fala de Dilma Rousseff:

4 DILMA ROUSSEFF: O senhor é o primeiro a falar em corrupção, mas eu posso enumerar todos os processos de vocês [políticos integrantes do PSDB, partido do adversário] que nunca foram julgados e as pessoas estão soltas.

No trecho, o ato "O senhor é o primeiro a falar em corrupção" leva à conclusão de que o adversário tem legitimidade para fazer acusações de corrupção. Essa conclusão é benéfica para a face do adversário e prejudicial para a face da candidata, uma vez que, em um debate, elogiar o adversário é depreciar-se (Fracchiolla 2011). Se ela não estabelecesse a relação de contraargumento marcada pelo mas, eleitores poderiam iniciar uma negociação secundária com objeções prejudiciais para a face da candidata e benéficas para a face do adversário, objeções como: "Então, ele tem legitimidade para fazer acusações de corrupção?".

\footnotetext{
${ }^{15}$ Essa análise se beneficia da descrição proposta por Ducrot (Ducrot et al. 1980) para o mais (mas). Conforme essa descrição, o conector introduz uma proposição Q que leva a uma conclusão (não-R) que é mais forte do que a conclusão $(R)$ a que leva a proposição $P$ que antecede o conector.
} 
Em resposta às objeções, a candidata, para tentar salvar sua própria face, precisaria produzir uma reação negativa: "Não. Eu posso enumerar todos os processos deles que nunca foram julgados e as pessoas estão soltas." Com a relação de contra-argumento, a candidata tenta evitar uma troca reparadora como essa, porque, opondo-se à conclusão derivada do ato à esquerda do conector, bloqueia o ataque à sua própria face e à de eleitores e ataca a do adversário.

Com as análises das relações de argumento (porque) e contra-argumento (mas), verifica-se seu papel na dimensão dramatúrgica do debate protagonizado por Dilma Rousseff e Aécio Neves. Utilizando essas relações e suas marcas no processo de figuração, os candidatos se antecipam a objeções que seriam prejudiciais para as imagens que reivindicam de figuras políticas competentes e idôneas, tentando elaborar intervenções que contribuam para a construção dessas imagens e que não sejam avaliadas como excessivamente ofensivas pelo adversário, mas, em especial, pelos eleitores.

\section{Considerações finais}

Neste trabalho, propusemos os elementos de uma abordagem interacionista para o estudo do papel das relações de discurso e de suas marcas na dimensão dramatúrgica do discurso. Conforme a hipótese que subjaz a essa abordagem, as relações de discurso que o locutor estabelece, ao produzir sua intervenção, permitem a ele antecipar-se a possíveis objeções do outro (interlocutor ou terceiro) quanto à natureza ofensiva dessa intervenção, para fazer com que o outro não a avalie como um ataque à sua face ou uma invasão de seu território. Estabelecendo relações, o locutor tenta impedir, assim, que o outro inicie uma troca reparadora, troca sempre perigosa para sua face e seu território.

Para chegarmos a essa proposta, articulamos um conjunto definido de conceitos, tais como contexto e dimensão dramatúrgica, interação (processo de negociação), relações de discurso e processo de figuração. Com base nesses conceitos, procuramos revelar o papel de relações de discurso na dimensão dramatúrgica de um debate eleitoral, evidenciando como o uso que os candidatos fazem das relações de argumento (porque) e contra-argumento (mas) Ihes permite construírem conjuntamente imagens identitárias, em função do modo como querem ser vistos pelos adversários, mas, sobretudo, pelos eleitores.

A proposta aqui apresentada deve ser entendida como a base para uma abordagem que possibilite a compreensão ampla do papel das relações de discurso e de suas marcas na dimensão dramatúrgica do discurso, compreensão que as abordagens focadas nos aspectos estruturais e informacionais dessas relações não permitem alcançar. Esta proposta constitui, desse modo, o ponto de partida para o estudo detalhado do modo como os interactantes, desenvolvendo o processo de construção conjunta de imagens identitárias, decidem estabelecer ou não determinada relação, utilizam diferentes marcas de um mesmo tipo de relação, escolhem marcar ou não as relações etc. 
Por lançarem luz sobre fenômenos que extrapolam os aspectos estritamente informacionais e estruturais das relações de discurso, as proposições reunidas neste trabalho permitem vislumbrar uma abordagem que, em uma perspectiva interacionista dos estudos da linguagem, possa descrever de forma sistemática o papel das relações de discurso e de suas marcas na dimensão dramatúrgica de todo e qualquer contexto.

\section{Referências bibliográficas}

Adam, Jean-Michel. 2006. La linguistique textuelle: introduction à I'analyse textuelle des discours, Paris, Armand Colin.

Aquino, Zilda Gaspar Oliveira de. 2008. Diálogos da mídia - o debate televisivo, em D. Preti (ed.), Diálogos na fala e na escrita, São Paulo, Humanitas: 171-194.

Austin, John Langshaw. 1962. How to do things with words, Oxford, Clarendon Press.

Blas-Arroyo, José Luis. 2003. "Perdóneme que se lo diga, pero vuelve usted a faltar a la verdad, señor Gonzáles": form and function of politic verbal behavior in face-to-face Spanish political debates. Discourse \& Society, 14, 4: 395-423.

Bousfield, Derek. 2018. Face(t)s of self and identity in interaction. Journal of Politeness Research, 14, 2: 287-305.

Bronckart, Jean-Paul. 2007. Atividade de linguagem textos e discursos: por um interacionismo sócio-discursivo, São Paulo, EDUC.

Brown, Penelope e Stephen C. Levinson. 1987. Politeness: some universals in language use, Cambridge, Cambridge University Press.

Culpeper, Jonathan. 1996. Towards an anatomy of impoliteness. Journal of Pragmatics, 25, 3: 349-367.

Culpeper, Jonathan. 2008. Reflections on impoliteness, relational work and power, em D. Bousfield e M. A. Locher (eds.), Impoliteness in language: studies on its interplay with power in theory and practice, Berlin, Mouton de Gruyter: 22-53.

Culpeper, Jonathan. 2011. Politeness and impoliteness, em K. Aijmer e G. Andersen (orgs.), Handbooks of Pragmatics: Sociopragmatics, Berlin, Mouton de Gruyter: 391-436.

Culpeper, Jonathan e Marina Terkourafi. 2017. Pragmatic approaches (im)politeness, em J. Culpeper, M. Haugh e D. Z. Kádár (eds.), The Palgrave Handbook of Linguistic (Im)politeness, London, Palgrave: 11-38.

Cunha, Gustavo Ximenes. 2012. Uma proposta para o tratamento das relações de discurso temporais no Modelo de Análise Modular do Discurso. Revista do GEL, 9: 29-49.

Cunha, Gustavo Ximenes. 2013. A construção da narrativa em reportagens, Tese de Doutorado, Universidade Federal de Minas Gerais, Belo Horizonte. [em linha] Disponível em http://www.letras.ufmg.br/padrao_cms/documentos/profs/gustavoximene s/Tese $\% 20$ A $\% 20$ construcao\%20da\%20narrativa\%20em\%20reportagens. pdf 
Cunha, Gustavo Ximenes. 2017a. O papel dos conectores na co-construção de imagens identitárias: o uso do mas em debates eleitorais. $A L F A, 61,3$ : 599-623.

Cunha, Gustavo Ximenes. 2017b. Conectores e processo de negociação: uma proposta discursiva para o estudo dos conectores. Fórum Linguístico, 14: 1699-1716.

Cunha, Gustavo Ximenes e Paloma Bernardino Braga. 2016. O comentário metadiscursivo como estratégia argumentativa em debates eleitorais. EID\&A, 12: 101-118.

Ducrot, Oswald, Sylvie Bruxelles, Éric Fouquier, Jean Gouazé, Géraldo Dos Reis Nunes, Anna Rémis, Anne-Marie Diller, Christine Sirdar-Iskandar, Danièle Bourcier, Luc Maury, Thanh Binh Nguyen, Laurence Ragunet de Saint Alban) 1980. Les mots du discours, Paris, Minuit.

Durkheim, Émile. 1996. As formas elementares da vida religiosa (Tr. de Paulo Neves) São Paulo, Martins Fontes.

Filliettaz, Laurent. 2000. Actions, activités et discours. Tese de Doutorado, Universidade de Genebra, Genebra. Inédita.

Filliettaz, Laurent. 2003. Textualisation et cadrage des activités: une analyse praxéologique des interactions de service, em H. Mari (ed.), Análise do discurso em perspectivas, Belo Horizonte, Faculdade de Letras da UFMG: 179-213.

Filliettaz, Laurent. 2004. Négociation, textualisation et action: le concept de négociation dans le modèle genevois de l'organisation du discours, em $M$. Grosjean e L. Mondada (eds.), La négociation au travail, Lyon, Presses universitaires de Lyon: 69-96.

Filliettaz, Laurent. 2006. La place du contexte dans une approche praxéologique du discours: le cas de l'argumentation dans les interactions scolaires. Pratiques 129-130: 71-88.

Filliettaz, Laurent, Isabelle Durand e Dominique Trébert. 2018. Dos processos de figuração às configurações de participação na interação: reflexões relacionais para a formação profissional, em G. X. Cunha e A. L. A. M. Oliveira (eds.), Múltiplas perspectivas do trabalho de face nos estudos da linguagem, Belo Horizonte, FALE/POSLIN/UFMG.

Fracchiolla, Béatrice. 2011. Politeness as strategy of attack in a gendered political debate - the Royal-Sarkosy debate. Journal of Pragmatics, 43: 2480-2488.

Goffman, Erving. 1973. La mise em scène de la vie quotidienne: les relations em public, Vol. 2, Paris, Les Éditions de Minuit.

Goffman, Erving. 1981. Forms of talk, Philadelphia, University of Pennsylvania Press.

Goffman, Erving. 2009 A representação do eu na vida cotidiana (Tr. de Maria Célia Santos Raposo), Petrópolis, Vozes.

Goffman, Erving. 2011. Ritual de interação: ensaios sobre o comportamento face a face (Tr. de Fabio Rodrigues Ribeiro da Silva), Petrópolis, Vozes.

Grice, Herbert Paul. 1975. Logic and conversation, em P. Cole e J. L. Morgan (eds.) Sintax and semantics, New York, Academic Press: 41-58.

Halliday, Michael Alexander Kirkwood e Ruqaiya Hasan. 1976. Cohesion in English, London, Longman. 
Harris, Sandra. 2011. The limits of politeness re-visited: courtroom discourse as a case in point, em Linguistic Politeness Research Group (ed.), Discursive approaches to politeness, Berlin, Mouton de Gruyter: 85-108 Holtgraves, Thomas. 1994. Communication in context: effects of speaker status on the comprehension of indirect requests. Journal of experimental psychology: learning, memory and cognition, 20, 5: 1205-1218

Kerbrat-Orecchioni, Catherine. 1992. Les interactions verbales, Paris, Colin. Kerbrat-Orecchioni, Catherine. 1995. Introduction, en C. Kerbrat-Orecchioni e C. Plantin. (eds.), Le trilogue, Lyon, Presses Universitaires de Lyon: 1-28.

Koch, Ingedore G. Villaça. 2004. Introdução à Linguística Textual, São Paulo, Martins Fontes.

Lakoff, Robin. 1977. What you can do with words: politeness, pragmatics and performatives, em A. Rogers, B. Wall e J. P. Murphy (eds.) Proceedings of the Texas Conference on performatives, presuppositions and implicatures, Arlington, Center for Applied Linguistics: 94-120.

Landone, Elena. 2012a. Discourse markers and politeness in a digital forum in Spanish. Journal of Pragmatics, 44: 1799-1820.

Landone, Elena. 2012b. El alcance interpersonal de los marcadores del discurso en la dinámica conversacional: el ejemplo de la cortesía verbal. VERBA, 39: 301-313.

Landone, Elena. 2017. Inferencias relacionales y valores culturales en el estudio de los marcadores del discurso. Cuadernos AISPI, 10: 113-136.

Leech, Geoffrey. 1983. Principles of Pragmatics, London, Longman.

Leech, Geoffrey. 2014. The pragmatics of politeness, Oxford, Oxford University Press.

Locher, Miriam A. e Richard Watts. 2008. Relational work and impoliteness: negotiating norms of linguistic behavior, em D. Bousfield e M. A. Locher (eds.), Impoliteness in language: studies on its interplay with power in theory and practice, Berlin, Mouton de Gruyter: 77-99.

Mann, William C. e Sandra A. Thompson. 1986. Relational propositions in discourse, Discourse Processes, 9, 1: 57-90.

Marinho, Janice Helena Chaves e Gustavo Ximenes Cunha. 2015. Os conectores como sinalizadores do processo de negociação: uma abordagem cognitivo-interacionista, (Con)Textos Linguísticos, 9: 75-94.

Martel, Guylaine. 2008. Performance... et contre-performance communicationnelles: des stratégies argumentatives pour le débat politique télévisé, Argumentation et Analyse du Discours, 1:,2-12.

Morato, Edwiges. 2004. O interacionismo no campo linguístico, em F. Mussalim e A. C. Bentes, Introdução à Linguística: fundamentos epistemológicos, São Paulo, Cortez. 311-352.

Neves, Maria Helena de Moura. 2006. Gramática e texto, São Paulo, Contexto. Roulet, Eddy. 1980. Stratégies d'interaction, modes d'implication et marqueurs illocutoires. Cahiers de linguistique française, 1: 80-103.

Roulet, Eddy. 1986. Complétude interactive et mouvements discursifs. Cahiers de linguistique française, 7: 189-206.

Roulet, Eddy. 1988. Variations sur la structure de l'échange langagier dans différentes situations d'interaction. Cahiers de linguistique française, 9, 1: 27-37. 
Roulet, Eddy. 1992. On the structure of conversation as negotiation, em $\mathrm{H}$. Parret e J. Verschueren (eds.), (On) Searle on conversation, Amsterdam, John Benjamins: 91-100.

Roulet, Eddy. 1995. Etude des plans d'organisation syntaxique, hiérarchique et référentiel du dialogue: autonomie et interrelations modulaires. Cahiers de linguistique française, 17: 123-140.

Roulet, Eddy. 1999. La description de I'organisation du discours: du dialogue au texte, Paris, Didier.

Roulet, Eddy. 2003. Une approche modulaire de la problematique des relations de discours, em H. Mari (ed.), Análise do discurso em perspectivas, Belo Horizonte, FALE/UFMG: 149-178.

Roulet, Eddy. 2006. The description of text relation markers in the Geneva model of discourse organization, em K. Fischer (ed.), Approaches to Discourse Particles, Amsterdam, Elsevier: 115-131.

Roulet, Eddy, Antoine Auchlin, Jacques Moeschler, Christian Rubattel e Marianne Schelling. 1985. L'articulation du discours en français contemporain, Berne, Lang.

Roulet, Eddy, Laurent Filliettaz e Anne Grobet. 2001. Un modèle et un instrument d'analyse de l'organisation du discours, Berne, Lang.

Scollon, Ron e Suzanne Wong Scollon. 2001. Intercultural communication: a discourse approach, Oxford, Blackwell.

Searle, John R. 1995. Expressão e significado: estudos da teoria dos atos da fala, São Paulo, Martins Fontes.

Spencer-Oatey, Helen. 2007. Theories of identity and the analysis of face. Journal of Pragmatics, 39: 639-656.

Sullet-Nylander, Françoise e Malin Roitman. 2009. De la confrontation politicojournalistique dans les grands duels politiques télévisés: questions et préconstruits, em M. Burger, J. Jacquin e R. Micheli (eds.), Actes du colloque Le français parlé dans les médias: les médias et le politique: 0119.

Vion, Robert. 1992. La communication verbale: analyse des interactions, Paris, Hachette.

Watts, Richard J. 2003. Politeness, Cambridge, Cambridge University Press.

Watts, Richard J. 2005. Linguistic politeness research: Quo vadis?, em R. J. Watts, I. Sachiko e K. Ehlich (eds.) Politeness in Language: studies in its History, Theory and Practice, Berlin, Mouton de Gruyter: 11-47.

NOTA

O Autor é o único responsável do conteúdo e da forma deste artigo. 